\section{Nondestructive Leaf Area Estimation of Rabbiteye Blueberries}

\author{
D. Scott NeSmith \\ Department of Horticulture, Georgia Station, Griffin, GA 30223
}

Nondestructive measurements of plant growth, frequently of leaf area, are often desirable because continued use of the same plants over time can reduce variability in experiments as compared with destructive sampling. While empirical equations commonly are used to estimate leaf area, knowing equations that could be used without additional validation for specific crops would be helpful. This requires that several cultivars of a crop be evaluated to determine whether the measurements used to estimate leaf area would have broad application within that species. To this end, six rabbiteye blueberry ( Vaccinium ashei Reade) cultivars were selected to determine the accuracy of estimating leaf area from measurements of leaf length and width or from leaf length alone.

Leaf samples were obtained from 5-yearold plants of the cultivars Bluebelle, Briteblue, Climax, Delite, Tifblue, and Woodard. Thirty leaves, representing the range of sizes present on three to five plants of each cultivar, were sampled. An earlier sampling of $>100$ leaves of 'Tifblue' revealed that 30 leaves would be sufficient for each cultivar as long as the range of leaf sizes was covered. Leaf length (the distance from the point of petiole attachment to the stem to the tip of the leaf blade) and leaf width (the widest point on the leaf blade) were determined individually. Area of individual leaves was determined using a LI-COR leaf area meter (Model LI-3000; LI-COR, Lincoln, Neb.). Data were subjected to linear and nonlinear regression procedures.

Received for publication 22 Jan. 1991. The cost of publishing this paper was defrayed in part by the payment of page charges. Under postal regulations, this paper therefore must be hereby marked advertisement solely to indicate this fact.

'Assistant Professor. multiplied by their width.
Figure 1 presents the leaf area (square centimeters) for individual leaves as a function of the product of their length (centimeters) and width (centimeters). The cultivars were evaluated individually, and their slopes and intercepts did not differ at $P=0.05$. Hence, regression was run on data points from all cultivars collectively.

$$
\begin{aligned}
& \text { Leaf area }=0.31+0.62 \text { (leaf length } \times \\
& \text { leaf width) } \\
& r^{2}=0.95
\end{aligned}
$$

This equation was very similar to the equation presented for 'Woodard' by Crane and Davies (1988). Also, an equation for 'Tifblue' based on container plants at another location (unpublished) was not significantly different from Eq. [1]. Thus, it appears that Eq. [1] can be used to accurately estimate rabbiteye blueberry leaf area for various cultivars and locations.
Leaf length alone was also evaluated as an estimate of blueberry leaf area, as this has been shown to be a reliable estimate of leaf area in grapes (Elsner and Jubb, 1988: Manivel and Weaver, 1974). The best fit was a nonlinear equation of the form $\mathrm{Y}=\mathrm{Ae}^{\mathrm{Bx}}+$ $\mathrm{C}$, in which the coefficient of determination $\left(r^{2}\right)$ was 0.83 . The variation and degree of fit for leaf length alone demonstrated that it was not an acceptable estimation of leaf area.

The equation described, based on leaf length and width measurements, should be useful in investigations where treatments might affect leaf expansion of rabbiteye blueberries, because the same plants can be monitored over time. Also, the procedure likely is a cost effective alternative to measurement of leaves by a more expensive leaf area meter.

\section{Literature Cited}

Crane, J.H. and F.S. Davies. 1988. Flooding duration and seasonal effects on growth and development of young rabbiteye blueberry plants. J. Amer. Soc. Hort. Sci. 113:180-184.

Elsner, E.A. and G.L. Jubb, Jr. 1988. Leaf area estimation of concord grape leaves from simple linear measurements. Amer. J. Enol. Viticult. 39:95-97.

Manivel, L. and R.J. Weaver. 1974. Biometric correlations between leaf area and length measurements of 'Grenache' grape leaves. HortScience 9:27-28.

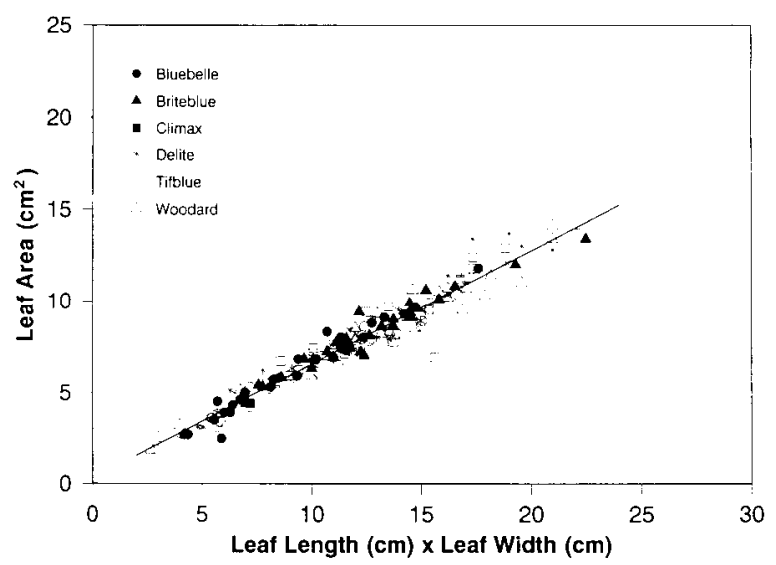

Fig. 1. Area of individual rabbiteye blueberry leaves from six cultivars as a function of their length 